\title{
Benefit finding in long-term prostate cancer survivors
}

\author{
Irène Lassmann $^{1} \cdot$ Andreas Dinkel $^{2}$ • Birgitt Marten-Mittag ${ }^{2} \cdot$ Matthias Jahnen $^{1} \cdot$ Helga Schulwitz ${ }^{1}$. \\ Jürgen E. Gschwend ${ }^{1} \cdot$ Kathleen Herkommer $^{1}$ (D)
}

Received: 17 September 2020 / Accepted: 22 December 2020 / Published online: 15 January 2021

(C) The Author(s) 2021

\begin{abstract}
Purpose Benefit finding (BF) represents possible positive changes that people may experience after cancer diagnosis and treatment and has proven to be valuable to the psychological outcome. Knowledge of such beneficial consequences of prostate cancer $(\mathrm{PCa})$ is limited in long-term survivors ( $>5$ years). Thus, the present study investigated the occurrence of benefit finding $(\mathrm{BF})$ and its determinants in a large sample of (very-) long-term PCa survivors.

Methods BF was assessed in 4252 PCa survivors from the German database "Familial Prostate Cancer" using the German version of the Benefit Finding Scale (BFS). Associations between BF and sociodemographic, clinical, and psychosocial (e.g., depressive and anxiety symptoms and perceived severity of the disease experience) variables were analyzed using hierarchical multiple linear regression analysis.

Results Mean age at survey was 77.4 years ( $\mathrm{SD}=6.2$ ) after a mean follow-up of 14.8 years ( $\mathrm{SD}=3.8$ ). Mean BFS score was 3.14 $(\mathrm{SD}=1.0$ ); the prevalence of moderate-to-high BF (score $\geq 3$ ) was $59.7 \%$. Younger age at diagnosis, lower educational level, and higher perceived severity of the disease experience were predictive of BF. Objective disease severity or family history of PCa was not uniquely associated with BF.

Conclusions BF occurs in older, (very-) long-term PCa survivors. Our findings suggest that the self-asserted severity of the disease experience in a patient's biography is linked to BF in the survivorship course above all tangible sociodemographic and clinical factors.

Implications for cancer survivors PCa survivors may express BF regardless of clinical disease severity. Treating urologists should consider inquiring $\mathrm{BF}$ to enrich a patient's cancer narrative.
\end{abstract}

Keywords Prostate cancer $\cdot$ Urological malignancy $\cdot$ Cancer survivor $\cdot$ Benefit finding $\cdot$ Posttraumatic growth

\section{Introduction}

Reevaluation of life and perception of positive changes after a stressful life event such as cancer have commonly been defined as benefit finding (BF) or posttraumatic growth (PTG) [1]. Reported positive outcomes may include an increased appreciation and acceptance of life, shifts in interpersonal relationships (family/friends), spiritual growth, strengthening of

Kathleen Herkommer

kathleen.herkommer@tum.de

1 Department of Urology, Klinikum rechts der Isar, School of Medicine, Technical University of Munich, Ismaninger Str. 22, 81675 Munich, Germany

2 Department of Psychosomatic Medicine and Psychotherapy, Klinikum rechts der Isar, School of Medicine, Technical University of Munich, Langerstr. 3, 81675 Munich, Germany one's personality, or improvement in health behaviors [2]. Both concepts, BF and PTG, share relevant features, and thus, these terms are often used interchangeably [1, 3-5]. Studies that investigated the relation among both constructs found a strong association, e.g., $r=0.71$ in the study by Jansen et al. [6]. Moreover, metaanalyses investigating whether the results were moderated by measures assessing BF vs. PTG did not find an effect, suggesting that associations are largely comparable for BF and PTG. This metaanalytic evidence revealed as well that BF and PTG showed a small positive association with posttraumatic stress [5, 7]. Furthermore, small associations were reported for enhanced positive well-being, while the association between BF or PTG and negative mental health as well as subjective physical health remains inconclusive $[1,3]$. Associations with objective physical health-related outcomes are also inconclusive; decreased stress-related biomarkers (i.e., healthier diurnal cortisol pattern and lymphocytes proliferation) have been described singularly $[8,9]$. 
However, improved global outcomes (e.g., reduced recurrence rates) have not been associated with $\mathrm{BF}$ and PTG. Regarding determinants of positive change after critical events, frequently though not unanimously reported sociodemographic characteristics include younger age at disease onset, female gender, and non Caucasian ethnicity in ethnic diverse study populations [1]. The objective severity of the disease has occasionally been linked to the perception of benefits. In a mixed sample of 83 cancer patients, Lechner et al. [4] described a curvilinear association between BF level and tumor stage. Moreover, higher perceived stress, perceived poor health, and perceived threat or burden arising from the disease was associated with BF and PTG [6, 10-12]. Furthermore, active coping, positive reappraisal, social support, and optimism $[1,10,13,14]$ but also intrusive thoughts and social constraints [14] showed significant associations with such positive changes. Most studies focused on shortterm cancer survivors ( $\leq 5$ years). However, Jansen et al. [6] reported a prevalence rate of $46-64 \%$ for BF and PTG in colorectal cancer survivors at a 5-year follow-up, and Lelorain et al. [15] found similar levels of PTG in long-term breast cancer survivors ( $5-15$ years after diagnosis) compared with short-term survivors.

Prostate cancer $(\mathrm{PCa})$ is the most common noncutaneous malignancy and a leading cause of cancer-related deaths in men in most Western countries [16]. In Germany, the median age of affected individuals at diagnosis is 72 years. The longterm survival rate of $\mathrm{PCa}$ is $88 \%$ at 10 -year follow-up, all stages combined [17]. Besides age and ethnicity, another known risk factor is a positive family history of $\mathrm{PCa}$ in approximately $20 \%$ of the cases [18]. PCa is diagnosed in $62 \%$ of cases in an organ-confined stage and can be treated with a curative intent [17]. However, 15-45\% of patients experience biochemical recurrence (BCR) during follow-up: initially low or undetectable levels of prostate-specific antigen (PSA) after primary therapy will rise again, indicating probable local relapse or occurrence of metastasis. Even after 10 years of BCRfree survival, BCR will occur in approximately $10 \%$ of patients [19]. Hence, annual follow-up visits are recommended even in (very-) long-term survivors [20]. Furthermore, side effects from both primary treatment and androgen deprivation therapy can have a negative impact on the quality of life [21, 22]. Moreover, up to $20 \%$ of long-term PCa survivors experience some kind of cancer-related distress [23-25]. Therefore, PCa may be considered a chronic or longitudinal stressor.

BF and PTG have been reported in PCa survivors using active coping strategies and receiving social and emotional support [26-28]. However, these studies comprised only patients with short follow-up periods (up to 18 months posttreatment) or time since diagnosis was not reported. Besides these factors, clinical variables like BCR and family history might be associated with positive changes in life after PCa.
Associations with such variables might be helpful for understanding and promoting personal growth in the survivorship trajectory, but have, to our knowledge, not yet been reported.

Thus, the present study investigated the occurrence of BF in a large sample of (very-) long-term PCa survivors and the associations of $\mathrm{BF}$ with sociodemographic, clinicopathological, and psychosocial characteristics.

\section{Methods}

\section{Study design}

This is a cross-sectional study conducted under the German nationwide research project "Familial Prostate Cancer". This project has been recruiting patients with PCa since 1993. The project aims to identify genetic and exogenous risk factors for $\mathrm{PCa}$ and to compare the clinical course and survivorship of patients with and without a family history of PCa. Briefly, patients are recruited by treating urologists or rehabilitation clinics mostly after radical prostatectomy (RP), and written consent is obtained. Sociodemographic and family history data are gathered via self-reporting questionnaires; clinical and histopathological data are reported by each patient's treating urologist. Mailed follow-up questionnaires, including questions to assess the current PSA level, a potentially ongoing treatment of the $\mathrm{PCa}$ and current family history of $\mathrm{PCa}$, are sent to the patients annually. Additionally, various psychosocial aspects have been investigated in the past years [23, 24].

\section{Procedure}

From October 2018 to November 2018, annual follow-up questionnaires, along with a prepaid return envelope, were sent to 6379 patients with known histopathological record and at least one returned follow-up questionnaire in the past. By June 2019, 4252 participants (67\%) had returned the questionnaire.

\section{Measures}

\section{Sociodemographic and clinicopathological characteristics}

Sociodemographic data included in this analysis were age at survey, partnership, educational level, and number of children. Clinical data included age at diagnosis, time since diagnosis, presence of a second primary cancer, family history of $\mathrm{PCa}$ (yes [at least one consanguine relative with $\mathrm{PCa}$ ] vs. no), PSA level at diagnosis, histopathological Gleason score, histopathological grading, organ-confined stage at RP according to the TNM classification of 2002, type of primary treatment, and ongoing treatment for $\mathrm{PCa}$ at survey. Biochemical 
recurrence after RP was defined as PSA level of $\geq 0.2 \mathrm{ng} / \mathrm{ml}$ and was analyzed for the entire follow-up period and at survey.

\section{Benefit finding}

The main outcome variable Benefit finding (BF) was assessed using the German version of the 17-item Benefit Finding Scale (BFS). The original version of the BFS, developed for a breast cancer population, and its German translation have proven to be a valid and reliable instrument and have shown a unidimensional structure [29-31]. We adapted the BFS by modifying the original stem to "having had prostate cancer". The stem is followed by 17 items describing potential beneficial consequences of the disease, that is, changes in interpersonal/familial relationships, acceptance of the deficiencies in life, or spiritual growth. Responses to each item are scored on a five-point Likert scale ranging from 1 (not at all) to 5 (extremely). [29] Strong endorsement of an item was defined as a score of $\geq 4$ (quite a bit), as previously described $[32,33]$. Prevalence of moderate-to-high BF was defined as a mean scale score of $\geq 3$ (moderately), as previously described [6]. Cronbach's alpha coefficient for this sample was 0.96 , indicating high internal consistency.

\section{Depressive and anxiety symptoms}

Psychological distress was assessed using the validated ultrabrief instruments Patient Health Questionnaire-2 (PHQ-2) for depressive symptoms and Generalized Anxiety Disorder-2 (GAD-2) scale for symptoms of anxiety. For both scales, a cutoff score of $\geq 3$ (range, $0-6$ ) indicates a clinical level of symptom burden [34]. Cronbach's alpha coefficients for the PHQ-2 and GAD-2 scales were 0.76 and 0.76 , respectively, indicating satisfactory internal consistency.

\section{Perceived severity of the disease experience}

The perceived severity of the disease experience as a stressful life event was assessed with the item "Having had prostate cancer is one of the worst things that happened to me in my life" (adapted from [35]). The participants were asked to rate this statement on a 4-point Likert scale ranging from 1 (strongly disagree) to 4 (strongly agree). Agreement/disagreement with this statement was used as operationalization of perceived severity of the disease experience, ranging from none to high.

\section{Statistical analysis}

Descriptive statistics were computed for all study variables. Prorating was used to impute up to 4 missing out of 17 items (23.5\%) of the BFS using the mean score of the participant's remaining items. Correlations between $\mathrm{BF}$ and psychosocial variables were reported as Pearson correlation coefficients. Hierarchical multiple regression analysis was conducted to predict BF via sociodemographic (step 1), clinical (step 2), and psychosocial (step 3) variables. All analyses were conducted using the Statistical Package for the Social Sciences, version 24 (IBM Corp., Chicago, IL, USA).

\section{Results}

\section{Sample characteristics}

The mean age of the 4252 PCa survivors who returned the questionnaire was $M=77.4$ years $(\mathrm{SD}=6.4)$. The participants were mostly living in a partnership (85.4\%), and $88.4 \%$ of them had at least one child. Among all participants, $29.4 \%$ held an academic degree, whereas $41.3 \%$ had a low educational level. The mean time since diagnosis of PCa was $M=$ 14.8 years $(\mathrm{SD}=3.8)$, and approximately $8 \%$ had survived for more than 20 years; $38.5 \%$ had a positive family history of $\mathrm{PCa}$. Surgery (RP) was the primary treatment for $97.9 \%$ of the patients, which is due to recruitment procedures for the database. During the follow-up period, BCR occurred in more than a third (35.8\%) of the participants. BCR at survey was reported in every fifth patient (19.6\%), and $13.5 \%$ were under a current treatment. Only a minority of the patients had a clinical level of depressive $(7.5 \%)$ or anxiety $(6.1 \%)$ symptoms. More than half of the patients $(53.5 \%)$ reported a moderate or high perceived severity of the disease experience with high perceived severity for $25.1 \%$ of all patients (Table 1 ).

Total scores for the BFS were available for 3899 participants $(91.7 \%)$. A missing data analysis showed that the 353 participants not included were characterized by a higher age (at diagnosis and at survey), lower educational level, no partnership, and a longer time since diagnosis (all $p \leq 0.005$ ).

\section{Benefit finding endorsement and prevalence}

Descriptive data for the BFS are shown in Table 2. Strong endorsement of single items ranged from $20.9 \%$ (has led me to meet people who have become some of my best friends) to $63.8 \%$ (has taught me to adjust to things I cannot change). The mean overall BFS score was $M=3.14(\mathrm{SD}=1.00)$. The prevalence of moderate-to-high $\mathrm{BF}$ was $59.7 \%$.

\section{Associations among study variables}

Correlational analysis revealed marginal to low significant associations among BF and the psychosocial variables (Table 3). To predict BF, a hierarchical multiple regression analysis was conducted (Table 4). The time since diagnosis was found to have strong intercorrelation with age at diagnosis 
Table 1 Sociodemographic, clinical, and psychosocial characteristics of the study population $(n=4252)$

\begin{tabular}{|c|c|c|c|}
\hline & $\mathrm{M}(\mathrm{SD})$ & $n$ & $\%$ \\
\hline Age at survey (years) & $77.4(6.4)$ & & \\
\hline$\leq 70$ & & 558 & 13.1 \\
\hline$>70 \leq 80$ & & 2145 & 50.5 \\
\hline$>80$ & & 1549 & 36.4 \\
\hline \multicolumn{4}{|l|}{ Educational level } \\
\hline Low & & 1724 & 41.3 \\
\hline Intermediate & & 708 & 17.0 \\
\hline High & & 511 & 12.3 \\
\hline Academic degree & & 1229 & 29.4 \\
\hline \multicolumn{4}{|l|}{ Partnership } \\
\hline Yes & & 3590 & 85.4 \\
\hline No & & 615 & 14.6 \\
\hline
\end{tabular}

Children

$1.8(1.0)$

$\geq 1$

$480 \quad 11.6$

$3672 \quad 88.4$

$62.6(6.2)$

$\leq 55$

520

12.2

$>55 \leq 65$

2145

50.5

$>65$

1587

$14.8(3.8)$

$$
\begin{aligned}
& \leq 10 \\
& >10 \leq 15 \\
& >15 \leq 20 \\
& >20
\end{aligned}
$$

Second primary cancer

Yes

No

Family history of $\mathrm{PCa}$

Yes

2615

390

9.2

2017

47.4

1513

35.6

332

7.8

542

12.8

3710

87.2

No

38.5

PSA level at diagnosis (ng/ml)

$$
\leq 4
$$$$
>4 \leq 10
$$$$
>10
$$

375

2367

1194

1758

1401

359

39.8

7

8-10

Grading

G I

181

2779

1040

G II

G III

26.0

Organ-confined stage of disease

Yes

2926

70.0

No

1256

30.0

Type of primary treatment

Surgery

4162

97.9

Radiotherapy

Others
62

1.5

28 
Table 1 (continued)

\begin{tabular}{|c|c|c|c|}
\hline & $\mathrm{M}(\mathrm{SD})$ & $n$ & $\%$ \\
\hline \multicolumn{4}{|l|}{ Biochemical recurrence during follow-up } \\
\hline Yes & & 1520 & 35.8 \\
\hline No & & 2732 & 64,2 \\
\hline \multicolumn{4}{|l|}{ Biochemical recurrence at survey } \\
\hline Yes & & 831 & 19.6 \\
\hline No & & 3420 & 80.4 \\
\hline \multicolumn{4}{|l|}{ Ongoing treatment at survey } \\
\hline Yes & & 570 & 13.5 \\
\hline No & & 3665 & 86.5 \\
\hline Clinical level of depressive symptoms (PHQ-2) & $0.81(1.16)$ & & \\
\hline Yes & & 300 & 7.5 \\
\hline No & & 3716 & 92.5 \\
\hline Clinical level of anxiety symptoms (GAD-2) & $0.71(1.07)$ & & \\
\hline Yes & & 244 & 6.1 \\
\hline No & & 3743 & 93.9 \\
\hline Perceived severity of the disease experience & $2.65(1.00)$ & & \\
\hline None & & 562 & 13.9 \\
\hline Low & & 1321 & 32.6 \\
\hline Moderate & & 1151 & 28.4 \\
\hline High & & 1017 & 25.1 \\
\hline
\end{tabular}

$M$, mean; $S D$, standard deviation; $P C a$, prostate cancer; $P S A$, prostate specific antigen; $R P$, radical prostatectomy; $P H Q-2$, Patient Health Questionnaire-2; GAD-2, Generalized Anxiety Disorder-2 scale

and age at survey, which led to its removal from the regression analysis model. Step 1 included all sociodemographic variables, accounting for $4.8 \%$ of the explained variance. Lower age at diagnosis, higher age at survey, and lower educational level predicted the mean BFS score (all $p<0.01$ ). Clinical variables were added in step 2 without increasing the
Table 2 Benefit finding items, mean scores, and strong endorsement frequencies $(n=$ 3877-4011)

\begin{tabular}{lllll}
\hline Item & Having had prostate cancer... & M & SD & $\% \geq 4$ \\
\hline 1 & has led me to be more accepting of things & 3.32 & 1.21 & 50.6 \\
2 & has taught me how to adjust to things I cannot change & 3.63 & 1.24 & 63.8 \\
3 & has helped me take things as they come & 3.56 & 1.24 & 60.2 \\
4 & has brought my family closer together & 3.08 & 1.38 & 43.5 \\
5 & has made me more sensitive to family issues & 3.17 & 1.29 & 46.8 \\
6 & has taught me that everyone has a purpose in life & 3.00 & 1.41 & 42.8 \\
7 & has shown me that all people need to be loved & 3.54 & 1.38 & 59.5 \\
8 & has made me realize the importance of planning for my family's future & 3.47 & 1.38 & 57.1 \\
9 & has made me more aware and concerned for the future of all human beings & 2.92 & 1.32 & 38.6 \\
10 & has taught me to be patient & 3.27 & 1.27 & 48.5 \\
11 & has led me to deal better with stress and problems & 3.10 & 1.26 & 43.2 \\
12 & has led me to meet people who have become some of my best friends & 2.31 & 1.27 & 20.9 \\
13 & has contributed to my overall emotional and spiritual growth & 2.75 & 1.28 & 31.9 \\
14 & has helped me become more aware of the love and support available & 3.26 & 1.32 & 48.7 \\
\cline { 2 - 2 } & $\quad$ from other people & & & \\
15 & has helped me realize who my real friends are & 2.92 & 1.45 & 40.5 \\
16 & has helped me become more focused on priorities, with a deeper & 2.98 & 1.36 & 41.3 \\
& sense of purpose in life & & \\
& has helped me become a stronger person, more able to cope & 3.18 & 1.37 & 47.7 \\
& effectively with future life challenges & & & \\
\hline
\end{tabular}

$M$, mean; $S D$, standard deviation 
Table 3 Correlations between benefit finding and psychosocial variables
Table 4 Hierarchical regression analysis for the mean Benefit Finding Scale score $(n=3297)$

\begin{tabular}{lccc}
\hline & Benefit finding & Perceived severity & Depressive symptoms \\
\hline Benefit finding & - & & \\
Perceived severity & $0.232 * * *$ & - & \\
Depressive symptoms & $0.047 * *$ & $0.210 * * *$ & $0.646 * * *$ \\
Anxiety symptoms & $0.081 * * *$ & $0.201 * * *$ & - \\
\hline
\end{tabular}

Benefit finding, Benefit Finding Scale; Perceived severity, perceived severity of the cancer experience; Depressive symptoms, Patient Health Questionnaire-2, Anxiety symptoms, Generalized Anxiety Disorder-2 scale; $* * p<0.01$, $* * * p<0.001$

\begin{tabular}{|c|c|c|c|c|c|c|}
\hline Step & & $B$ & SE $B$ & $\beta$ & Adj. $R^{2}$ & $\Delta R^{2}$ \\
\hline \multirow[t]{5}{*}{1} & Sociodemographics & & & & 0.048 & $0.049 * * *$ \\
\hline & $\begin{array}{l}\text { Age at survey } \\
\text { School education }\end{array}$ & $\begin{array}{r}0.015 \\
-0.125\end{array}$ & $\begin{array}{l}0.005 \\
0.010\end{array}$ & $\begin{aligned} & 0.095 * * \\
- & 0.212 * * *\end{aligned}$ & & \\
\hline & Partnership & 0.051 & 0.050 & 0.017 & & \\
\hline & Children $^{\dagger}$ & 0.022 & 0.017 & 0.022 & & \\
\hline & Age at diagnosis ${ }^{\dagger}$ & -0.022 & 0.005 & $-0.135 * * *$ & & \\
\hline \multirow[t]{11}{*}{2} & + Clinical variables & & & & 0.051 & $0.005 *$ \\
\hline & $\begin{array}{l}\text { Age at survey }{ }^{\dagger} \\
\text { School education }\end{array}$ & $\begin{array}{r}0.013 \\
-0.122\end{array}$ & $\begin{array}{l}0.005 \\
0.010\end{array}$ & $\begin{aligned} & 0.085 * * \\
- & 0.208 * * *\end{aligned}$ & & \\
\hline & Partnership ${ }^{\ddagger}$ & 0.051 & 0.050 & 0.017 & & \\
\hline & Children $^{\dagger}$ & 0.024 & 0.017 & 0.024 & & \\
\hline & Age at diagnosis ${ }^{\dagger}$ & -0.021 & 0.005 & $-0.128 * * *$ & & \\
\hline & Second primary cancer ${ }^{*}$ & -0.033 & 0.051 & -0.011 & & \\
\hline & Family history of $\mathrm{PCa}^{\ddagger}$ & -0.063 & 0.035 & -0.030 & & \\
\hline & PSA level at diagnosis ${ }^{\dagger}$ & -0.001 & 0.001 & -0.010 & & \\
\hline & Biochemical recurrence during $\mathrm{FU}^{*}$ & 0.083 & 0.050 & 0.039 & & \\
\hline & Biochemical recurrence at survey ${ }^{\ddagger}$ & -0.001 & 0.058 & 0.000 & & \\
\hline & Ongoing treatment at survey ${ }^{\star}$ & 0.101 & 0.057 & 0.034 & & \\
\hline \multirow[t]{15}{*}{3} & + Psychosocial variables & & & & 0.96 & $0.046 * * *$ \\
\hline & Age at survey ${ }^{\dagger}$ & 0.014 & 0.005 & $0.092 * *$ & & \\
\hline & School education ${ }^{\dagger}$ & -0.107 & 0.010 & $-0.181 * * *$ & & \\
\hline & Partnership & 0.041 & 0.049 & 0.014 & & \\
\hline & Children $^{\dagger}$ & 0.036 & 0.016 & $0.037 *$ & & \\
\hline & Age at diagnosis ${ }^{\dagger}$ & -0.018 & 0.005 & $-0.113 * * *$ & & \\
\hline & Second primary cancer ${ }^{*}$ & -0.007 & 0.050 & -0.002 & & \\
\hline & Family history of $\mathrm{PCa}^{\ddagger}$ & -0.044 & 0.035 & -0.021 & & \\
\hline & PSA level at diagnosis ${ }^{\dagger}$ & -0.001 & 0.001 & -0.016 & & \\
\hline & Biochemical recurrence during $\mathrm{FU}^{\ddagger}$ & 0.049 & 0.049 & 0.024 & & \\
\hline & Biochemical recurrence at survey & 0.006 & 0.057 & 0.002 & & \\
\hline & Ongoing treatment at survey ${ }^{*}$ & 0.089 & 0.056 & 0.030 & & \\
\hline & Depressive symptoms (PHQ-2) ${ }^{\dagger}$ & -0.044 & 0.020 & $-0.051 *$ & & \\
\hline & Anxiety symptoms (GAD-2) ${ }^{\dagger}$ & 0.041 & 0.022 & 0.044 & & \\
\hline & Perceived severity ${ }^{\dagger}$ & 0.220 & 0.018 & $0.217 * * *$ & & \\
\hline
\end{tabular}

$S E$, standard error; $P C a$, prostate cancer; $P S A$, prostate specific antigen; $F U$, follow-up; $P H Q-2$, Patient Health Questionnaire-2; GAD-2, Generalized Anxiety Disorder-2 scale; Perceived severity, perceived severity of the disease experience

${ }^{\dagger}$ considered continuous variable; $\$$ scored $0=$ no, $1=$ yes

$* p<0.05, * * p<0.01, * * * p<0.001$ 
explained variance $\left(\Delta R^{2}=0.005\right)$. In the last step, the psychosocial variables were included. Higher perceived severity of the disease experience and lower level of depressive symptoms predicted $\mathrm{BF}$, adding $4.6 \%$ to the explained variance. In the final model, perceived severity of the disease experience and educational level were the strongest predictors of $\mathrm{BF}$ with $\beta$ coefficients of 0.217 and -0.181 , respectively (both $p<$ $0.001)$. The overall explained variance was $9.6 \%$.

\section{Discussion}

The present study mainly aimed to evaluate the occurrence of benefit finding (BF) in a large sample of long-term PCa survivors in Germany, as knowledge about BF could help promoting positive mental health in the survival course. Furthermore, associations of BF with a broad range of disease-related and psychosocial factors were investigated. Most notably, the perceived severity of the disease experience emerged as the variable most strongly associated with $\mathrm{BF}$, independently of the objective clinical severity of the disease course.

In the present study, moderate-to-high BF occurred in $60 \%$ of the PCa survivors after an average of 15 years since diagnosis. Our results suggest that being diagnosed with, treated for and surviving PCa can lead to the perceptions of benefits and to positive life changes in the long term. BF and PTG occurred in $50-93 \%$ of cancer survivors in various cancer populations $[33,36,37]$. The large variability of prevalence rates may partly be due to the different cancer entities themselves, but the impact of prevalence definition should also be considered. Although there is no general definition for the occurrence of meaningful, significant BF and PTG in cancer survivors, some studies have defined occurrence of positive changes when at least one benefit was reported, leading generally to higher reported rates [10]. Other studies, however, adopted a narrower definition using a quantitative tool, such as the Benefit Finding Scale (BFS) (i.e., the rate of patients reporting at least a moderate level of $\mathrm{BF}$ ). Applying the latter definition, similar prevalence rates have been found in survivors of meningioma and colorectal cancer $(63 \%$ and $64 \%$, respectively) but have not yet been reported in studies considering PCa survivors $[6,32]$. Instead, the mean single item and total scores are more frequently reported, allowing sample comparison. The mean total BFS score in our German study population was 3.1, whereas lower mean total BFS scores of 2.1 (unknown follow-up period) and 2.7 (mean of 10.5 months after treatment) in PCa survivors were previously reported in Australia and the USA, respectively [31, 38]. Differences in these levels could perhaps be due to the shorter follow-up periods, as BF and PTG are thought to require time to develop, allowing cognitive and emotional processes to unfold [1, 12, 39]. Additionally, cultural differences are conceivable. Indeed, similar results were found in German long-term colorectal cancer survivors (5-year follow-up) with a prevalence of moderate-to-high $\mathrm{BF}$ of $64 \%$ and a mean total BFS score of 3.4 [6].

Item endorsement ranking allows qualitatively exploring the appraisal of the different domains of BF. Items reflecting acceptance of and adjustment to the irrevocably changed things in life seem to regularly find the highest endorsement in different cancer populations including those in the present study. These benefits are followed or sometimes preceded by items reflecting enhanced existing relationships with family and friends $[31,32,40]$. In these rankings, the least endorsed item was virtually always "has led me to meet people who have become some of my best friends", which is the same in the present study. Thus, extending the social network (e.g., fellow patients in a self-support group) seems to be a rather marginal phenomenon after cancer diagnosis, while existing bonds increase in value and appreciation.

Associations between BF and PTG and sociodemographic factors have broadly been evaluated in the past decades. Inconsistent or even contradictory findings have been described as the result of variations in study design and population and the varying analyses of data $[1,40]$. Lower educational level and, to a smaller extent, younger age at diagnosis were predictive of BF in the present study population. Lower socioeconomic status, represented here by the educational level as a proxy, has repeatedly been linked to BF and PTG [26, $40,41]$. This association is believed to be due to the patients' experiences in dealing with disruption and hardships in life [41]. A weak, inverse association with age has been established and is considered to be moderated by higher distress along with greater optimism and openness for change in younger cancer patients [1, 42]. Indeed, even in a mixed sample of older adult long-term cancer survivors $(29.5 \%$ were PCa survivors; mean age 72.5 years), relatively younger survivors were more likely to report posttraumatic transformation [43]. The effect on BF of age at diagnosis in the present study population was weak. Studies involving PCa survivors could not corroborate this relationship [26, 28, 31]. The low variability of age at diagnosis in patients with $\mathrm{PCa}$ could be related to these inconsistent findings, as most men are diagnosed with $\mathrm{PCa}$ in ages older than 65 years.

We surveyed BF after a mean time since diagnosis of 14.8 years. To our knowledge, the present study is the first report of $\mathrm{BF}$ in PCa survivors with this extended follow-up period. Little is known about the stability of BF over long periods of time. However, when cautiously compared with the lower levels of $\mathrm{BF}$ in the short-term $\mathrm{PCa}$ survivors mentioned before, our findings seem to support the notion that BF has at least a stable component or could even increase over long periods of time. Accordingly, similar levels of growth were found in breast cancer survivors with 5-15 years postdiagnosis compared with shorter-term survivors in previous studies [15]. 
Following Tedeschi and Calhoun's concept of posttraumatic growth, the magnitude of the disrupting "seismic event" must be sufficiently severe to struggle with it and to engage in coping processes [39]. The magnitude or severity of a cancer disease can be considered in objective and self-reported subjective approaches. Objective parameters for the severity of the disease in previous studies included tumor stage, type of primary treatment, adjuvant treatment (like chemotherapy or tamoxifen in breast cancer patients), and impairing side effects. Objective severity, represented by the tumor stage, has been linked to BF and PTG in a (curvi-)linear association, reflecting that the disease should be sufficiently severe - but not too severe - to engage in coping processes leading to the perception of personal growth $[4,41]$. Adorno et al. [37] described the endorsement of distinctive domains of BF in patients with localized vs. spread disease. Other studies, however, could often not establish this association [33, 44]. These inconclusive findings could originate from variations in the operationalization of the variables or from the exclusion criteria of many studies (e.g., advanced stages). In studies including PCa survivors, BF and PTG were not associated with the type of primary treatment, differences in the antihormonal therapy regimen, or impaired sexual or urinary functioning [26-28, 40]. Further disease-related factors, such as disease recurrence or current therapy, represent additional stressors in the disease course and might therefore influence the extent of positive changes. However, this relationship did not emerge in the present study. Disease recurrence was defined on a biochemical level (i.e., increased PSA level $\geq 0.2$ $\mathrm{ng} / \mathrm{ml}$ after RP) and does not correspond to a clinical recurrence. Therefore, it might not necessarily reflect the patient's awareness of the disease progression. However, subsequent current therapy - one can assume is consciously perceivedwas not predictive for BF. Thus, patients might not perceive active treatment as a severe adversity, as action is taken to counteract disease recurrence or because they get more resilient over the course of the often-permanent treatment.

Furthermore, a positive family history of $\mathrm{PCa}$ or the presence of a second primary cancer may constitute additional factors contributing to distress that have, to our knowledge, not yet been investigated in PCa survivors. Alternatively, they could put one's current disease into perspective and hereby reduce its threat; for instance, sons of affected fathers could have observed a mild manifestation of the disease. Additionally, the long mean time since diagnosis in our study population could have reduced the impact of the family history on patient's current distress. Our null findings do not allow to draw firm conclusions about the effect of family history, and its effect should be investigated further in future studies.

High levels of perceived stress, threat, or disease intensity have indeed been established as a promoter of BF and PTG and illustrate the subjective side of the severity of the disease experience $[1,11,12,45]$. Previous operationalizations of threat and stress in recently diagnosed cancer patients represented their current and future views of the disease (e.g., rating of the subjective likeliness to die of cancer). A retrospective and biographical approach to this factor appeared to us to be more suitable in older long-term survivors. Therefore, we surveyed the perceived severity of the disease experience as an adverse life event asking, "Having had prostate cancer is one of the worst things that happened in my life". It was proven to be the primary predictive factor of $\mathrm{BF}$ in the present study population. Hence, our findings confirm and extend previous investigations of this relationship.

\section{Limitations}

There are some limitations to be addressed. First, the crosssectional design of the present study precludes temporal inferences. Longitudinal studies surveying trajectories of positive changes in the long-term survival course should be considered in future studies. Because of the recruitment procedures for the research project, patients after RP were clearly overrepresented in the present study sample. While previous data did not show an effect for primary treatment regimen in short-term PCa survivors [40], our findings cannot be generalized to radiotherapy or active surveillance/watchful waiting patients. Furthermore, there is another selection bias as our sample included only those patients who survived a very long time after their PCa diagnosis. Moreover, as we did not assess ethnicity, the relevance of sociocultural factors for our results pattern remains unclear. Although several potentially relevant factors were included in the analysis, the explained variance of the regression analysis was low. Other factors with the potential to promote BF and PTG (such as adaptive coping, optimism, resilience, or health-related quality of life) could not be evaluated, and thus, important links could have been missed. Finally, as we did not assess comorbidities or the occurrence of other critical or traumatic life events since PCa diagnosis and treatment, it is unclear whether the development of $\mathrm{BF}$ after $\mathrm{PCa}$ is also influenced by other, noncancer-related stressors.

\section{Conclusion and clinical implications}

In conclusion, the present study revealed that a large proportion of older (very-) long-term PCa survivors report benefits and growth arising from the disease. Our results suggest that the self-asserted meaning and subjective importance of the disease in the patient's biography are primarily linked to BF in the survivorship course.

Active exploration of BF and PTG should be considered by the treating clinician independently of the clinical severity of the patient's disease during the extended follow-up period, as 
promoting personal growth has been proven to be an important resource for mental health adjustment. Indeed, psychological intervention for PCa survivors showed positive effects on personal growth [38]. Still, it is important to acknowledge that finding benefit and meaning in the cancer experience is not prescriptive but represents an individual journey.

Authors' contribution The authors listed below have made substantial contributions to the intellectual content of the paper in the various sections described below.

Conception and design, A. Dinkel, K. Herkommer. Acquisition of data, I. Lassmann, H. Schulwitz, K. Herkommer. Analysis and interpretation of data, I. Lassmann, A. Dinkel, K. Herkommer. Drafting of the manuscript, I. Lassmann. Critical revision of the manuscript for important intellectual content, I. Lassmann, A. Dinkel, B. Marten-Mittag, M. Jahnen, H. Schulwitz, J.E. Gschwend, K. Herkommer. Statistical analysis, B. Marten-Mittag, H. Schulwitz. Administrative, technical, or material support, K. Herkommer, J. E. Gschwend. Supervision, A. Dinkel, K. Herkommer.

Funding information Open Access funding enabled and organized by Projekt DEAL.

Data availability The authors have full control of all primary data.

\section{Compliance with ethical standards}

Conflict of interest The authors declare that they have no conflict of interest.

Ethical approval All procedures conducted in studies involving human participants were according to the ethical standards of the institutional and/or national research committee and with the World Medical Association's 1964 Helsinki Declaration and its later amendments or comparable ethical standards.

Informed consent Informed consent was obtained from all individual participants included in the study.

Open Access This article is licensed under a Creative Commons Attribution 4.0 International License, which permits use, sharing, adaptation, distribution and reproduction in any medium or format, as long as you give appropriate credit to the original author(s) and the source, provide a link to the Creative Commons licence, and indicate if changes were made. The images or other third party material in this article are included in the article's Creative Commons licence, unless indicated otherwise in a credit line to the material. If material is not included in the article's Creative Commons licence and your intended use is not permitted by statutory regulation or exceeds the permitted use, you will need to obtain permission directly from the copyright holder. To view a copy of this licence, visit http://creativecommons.org/licenses/by/4.0/.

\section{References}

1. Helgeson VS, Reynolds KA, Tomich PL (2006) A meta-analytic review of benefit finding and growth. J Consult Clin Psychol 74(5): 797-816. https://doi.org/10.1037/0022-006X.74.5.797

2. Lechner SC (2018) Benefit-Finding. In: Snyder CR, Lopez SJ, Edwards LM, Marques SC (eds) The Oxford handbook of positive psychology, 3rd edn. Oxford University Press. [OnlineFirst]. https://doi.org/10.1093/oxfordhb/9780199396511.013.53.

3. Sawyer A, Ayers S, Field AP (2010) Posttraumatic growth and adjustment among individuals with cancer or HIV/AIDS: a metaanalysis. Clin Psychol Rev 30(4):436-447. https://doi.org/10.1016/ j.cpr.2010.02.004

4. Lechner SC, Zakowski SG, Antoni MH, Greenhawt M, Block K, Block P (2003) Do sociodemographic and disease-related variables influence benefit-finding in cancer patients? Psycho-Oncology 12(5):491-499. https://doi.org/10.1002/pon.671

5. Shand LK, Cowlishaw S, Brooker JE, Burney S, Ricciardelli LA (2015) Correlates of post-traumatic stress symptoms and growth in cancer patients: a systematic review and meta-analysis. PsychoOncology 24(6):624-634. https://doi.org/10.1002/pon.3719

6. Jansen L, Hoffmeister M, Chang-Claude J, Brenner H, Arndt V (2011) Benefit finding and post-traumatic growth in long-term colorectal cancer survivors: prevalence, determinants, and associations with quality of life. Br J Cancer 105(8):1158-1165. https:// doi.org/10.1038/bjc.2011.335

7. Marziliano A, Tuman M, Moyer A (2020) The relationship between post-traumatic stress and post-traumatic growth in cancer patients and survivors: a systematic review and meta-analysis. Psycho-Oncology 29(4):604-616. https://doi.org/10.1002/pon. 5314

8. Wang AW, Hoyt MA (2018) Benefit finding and diurnal cortisol after prostate cancer: the mediating role of positive affect. PsychoOncology 27(4):1200-1205. https://doi.org/10.1002/pon.4647

9. McGregor BA, Antoni MH, Boyers A, Alferi SM, Blomberg BB, Carver CS (2004) Cognitive-behavioral stress management increases benefit finding and immune function among women with early-stage breast cancer. J Psychosom Res 56(1):1-8. https://doi. org/10.1016/s0022-3999(03)00036-9

10. Sears SR, Stanton AL, Danoff-Burg S (2003) The yellow brick road and the emerald city: benefit finding, positive reappraisal coping and posttraumatic growth in women with early-stage breast cancer. Health Psychol 22(5):487-497. https://doi.org/10.1037/0278-6133. 22.5.487

11. Park CL, Cohen LH, Murch RL (1996) Assessment and prediction of stress-related growth. J Pers 64(1):71-105. https://doi.org/10. 1111/j.1467-6494.1996.tb00815.x

12. Cordova MJ, Cunningham LL, Carlson CR, Andrykowski MA (2001) Posttraumatic growth following breast cancer: a controlled comparison study. Health Psychol 20(3):176-185

13. Luszczynska A, Mohamed NE, Schwarzer R (2005) Self-efficacy and social support predict benefit finding 12 months after cancer surgery: the mediating role of coping strategies. Psychol Health Med 10(4):365-375. https://doi.org/10.1080/13548500500093738

14. Dunn J, Occhipinti S, Campbell A, Ferguson M, Chambers SK (2011) Benefit finding after cancer: the role of optimism, intrusive thinking and social environment. J Health Psychol 16(1):169-177. https://doi.org/10.1177/1359105310371555

15. Lelorain S, Bonnaud-Antignac A, Florin A (2010) Long term posttraumatic growth after breast cancer: prevalence, predictors and relationships with psychological health. J Clin Psychol Med Settings 17(1):14-22. https://doi.org/10.1007/s10880-009-9183-6

16. Bray F, Ferlay J, Soerjomataram I, Siegel RL, Torre LA, Jemal A (2018) Global cancer statistics 2018: GLOBOCAN estimates of incidence and mortality worldwide for 36 cancers in 185 countries. CA Cancer J Clin 68(6):394-424. https://doi.org/10.3322/caac. 21492

17. Robert Koch-Institut (2019) Prostata. In: Zentrum für Krebsregisterdaten, Gesellschaft der epidemiologischen Krebsregister in Deutschland, editors. Krebs in Deutschland für 2015/2016 [Cancer in Germany 2015/2016], 12 edn. Berlin, pp 98-101. https://doi.org/10.25646/5977. 
18. Hemminki K (2012) Familial risk and familial survival in prostate cancer. World J Urol 30(2):143-148. https://doi.org/10.1007/ s00345-011-0801-1

19. Liesenfeld L, Kron M, Gschwend JE, Herkommer K (2017) Prognostic factors for biochemical recurrence more than 10 years after radical prostatectomy. J Urol 197(1):143-148. https://doi.org/ 10.1016/j.juro.2016.07.004

20. Mottet N, van den Bergh RCN, Briers E, Cornford P, De Santis M, Fanti S et al (2019) EAU - EANM - ESTRO - ESUR - SIOG Guidelines on Prostate Cancer. presented at the EAU Annual Congress Barcelona 2019 ed. EAU Guidelines Office, Arnhem, pp 94-98

21. Potosky AL, Davis WW, Hoffman RM, Stanford JL, Stephenson RA, Penson DF, Harlan LC (2004) Five-year outcomes after prostatectomy or radiotherapy for prostate cancer: the prostate cancer outcomes study. J Natl Cancer Inst 96(18):1358-1367. https://doi. org/10.1093/jnci/djh259

22. Elliott S, Latini DM, Walker LM, Wassersug R, Robinson JW (2010) Androgen deprivation therapy for prostate cancer: recommendations to improve patient and partner quality of life. J Sex Med 7(9):2996-3010. https://doi.org/10.1111/j.1743-6109.2010.01902. $\mathrm{x}$

23. Dinkel A, Kornmayer M, Gschwend JE, Marten-Mittag B, Herschbach P, Herkommer K (2014) Influence of family history on psychosocial distress and perceived need for treatment in prostate cancer survivors. Familial Cancer 13(3):481-488. https://doi. org/10.1007/s10689-014-9715-6

24. Meissner VH, Herkommer K, Marten-Mittag B, Gschwend JE, Dinkel A (2017) Prostate cancer-related anxiety in long-term survivors after radical prostatectomy. J Cancer Surviv 11(6):800-807. https://doi.org/10.1007/s11764-017-0619-y

25. Baden M, Lu L, Drummond FJ, Gavin A, Sharp L (2020) Pain, fatigue and depression symptom cluster in survivors of prostate cancer. Support Care Cancer 28:4813-4824. https://doi.org/10. 1007/s00520-019-05268-0

26. Kinsinger DP, Penedo FJ, Antoni MH, Dahn JR, Lechner S, Schneiderman N (2006) Psychosocial and sociodemographic correlates of benefit-finding in men treated for localized prostate cancer. Psycho-Oncology 15(11):954-961. https://doi.org/10.1002/ pon. 1028

27. Pascoe EC, Edvardsson D (2016) Which coping strategies can predict beneficial feelings associated with prostate cancer? J Clin Nurs 25(17-18):2569-2578. https://doi.org/10.1111/jocn. 13300

28. Thornton AA, Perez MA (2006) Posttraumatic growth in prostate cancer survivors and their partners. Psycho-Oncology 15(4):285296. https://doi.org/10.1002/pon.953

29. Antoni MH, Lehman JM, Klibourn KM, Boyers AE, Culver JL, Alferi SM et al (2001) Cognitive-behavioral stress management intervention decreases the prevalence of depression and enhances benefit finding among women under treatment for early-stage breast cancer. Health Psychol 20(1):20-32. https://doi.org/10. 1037/0278-6133.20.1.20

30. Mohamed N, Böhmer S (2004) Die deutsche Version der Benefit Finding Skala: Ihre psychometrischen Eigenschaften bei Tumorpatienten [The German version of the Benefit Finding Scale: Psychometric properties in cancer patients]. Z Med Psychol 13(2):85-91

31. Pascoe L, Edvardsson D (2015) Psychometric properties and performance of the 17-item Benefit Finding Scale (BFS) in an outpatient population of men with prostate cancer. Eur J Oncol Nurs 19(2):169-173. https://doi.org/10.1016/j.ejon.2014.09.004
32. Kangas M, Williams JR, Smee RI (2011) Benefit finding in adults treated for benign meningioma brain tumours: relations with psychosocial wellbeing. Brain Impair 12(2):105-116

33. Harrington S, McGurk M, Llewellyn CD (2008) Positive consequences of head and neck cancer: key correlates of finding benefit. J Psychosoc Oncol 26(3):43-62. https://doi.org/10.1080/ 07347330802115848

34. Löwe B, Wahl I, Rose M, Spitzer C, Glaesmer H, Wingenfeld K, Schneider A, Brähler E (2010) A 4-item measure of depression and anxiety: validation and standardization of the Patient Health Questionnaire-4 (PHQ-4) in the general population. J Affect Disord 122(1-2):86-95. https://doi.org/10.1016/j.jad.2009.06.019

35. Vadaparampil ST, Jacobsen PB, Kash K, Watson IS, Saloup R, Pow-Sang J (2004) Factors predicting prostate specific antigen testing among first-degree relatives of prostate cancer patients. Cancer Epidemiol Biomark Prev 13(5):753-758

36. Sarna L, Padilla G, Holmes C, Tashkin D, Brecht ML, Evangelista L (2002) Quality of life of long-term survivors of non-small-cell lung cancer. J Clin Oncol 20(13):2920-2929. https://doi.org/10. 1200/jco.2002.09.045

37. Adorno G, Lopez E, Burg MA, Loerzel V, Killian M, Dailey AB, Iennaco JD, Wallace C, Sharma DKB, Stein K (2018) Positive aspects of having had cancer: a mixed-methods analysis of responses from the American Cancer Society Study of Cancer Survivors-II (SCS-II). Psycho-Oncology 27(5):1412-1425. https://doi.org/10.1002/pon.4484

38. Penedo FJ, Molton I, Dahn JR, Shen B-J, Kinsinger D, Traeger L, Siegel S, Schneiderman N, Antoni M (2006) A randomized clinical trial of group-based cognitive-behavioral stress management in localized prostate cancer: development of stress management skills improves quality of life and benefit finding. Ann Behav Med 31(3): 261-270. https://doi.org/10.1207/s15324796abm3103_8

39. Tedeschi RG, Calhoun LG (2004) Posttraumatic growth: conceptual foundations and empirical evidence. Psychol Inq 15(1):1-18

40. Weaver KE, Llabre MM, Lechner SC, Penedo F, Antoni MH (2008) Comparing unidimensional and multidimensional models of benefit finding in breast and prostate cancer. Qual Life Res 17(5):771-781. https://doi.org/10.1007/s11136-008-9348-z

41. Tomich PL, Helgeson VS (2004) Is finding something good in the bad always good? Benefit finding among women with breast cancer. Health Psychol 23(1):16-23. https://doi.org/10.1037/02786133.23.1.16

42. Aldwin CM, Levenson MR, Kelly L (2009) Life span developmental perspectives on stress-related growth. Medical illness and positive life change: can crisis lead to personal transformation? American Psychological Association, Washington, DC, pp 87104. https://doi.org/10.1037/11854-005.

43. Kahana B, Kahana E, Deimling G, Sterns S, VanGunten M (2011) Determinants of altered life perspectives among older-adult longterm cancer survivors. Cancer Nurs 34(3):209-218. https://doi.org/ 10.1097/NCC.0b013e3181fa56b0

44. Rinaldis M, Pakenham KI, Lynch BM (2010) Relationships between quality of life and finding benefits in a diagnosis of colorectal cancer. Br J Psychol 101(Pt 2):259-275. https://doi.org/10.1348/ 000712609X448676

45. Bellizzi KM, Blank TO (2006) Predicting posttraumatic growth in breast cancer survivors. Health Psychol 25(1):47-56. https://doi. org/10.1037/0278-6133.25.1.47

Publisher's note Springer Nature remains neutral with regard to jurisdictional claims in published maps and institutional affiliations. 